\title{
Human resource development using e-learning for Hungarian agricultural experts
}

\author{
Peter Lengyel ${ }^{1}$, István Füzesi² ${ }^{2}$ Ádám Péntek ${ }^{3}$, Miklós Herdon ${ }^{4}$
}

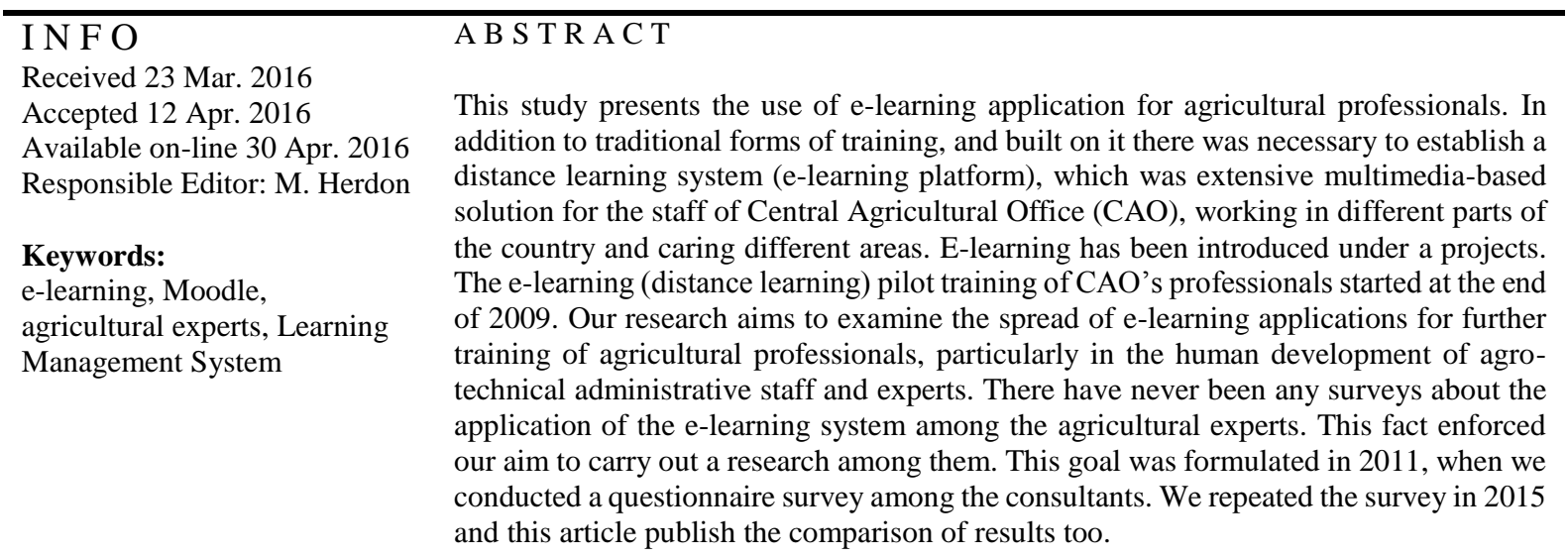

\section{Introduction}

After the millennium, many organizations operating in the agricultural sector recognized the opportunities provided by e-learning, including the National Food Chain Safety Office (NFCSO) and the Hermann Ottó Institution in Hungary, which was previously the Ministry of Rural Development, Rural Development Educational and Advisory Institute (MRD RDEAI).

The Central Agricultural Office (CAO) and the former Hungarian Food Safety Office (HFSO) were integrated into a new office establishing the NFCSO on 15th March 2012. From then on, the NFCSO operates as a legal successor of the CAO and the HFSO incorporating all aspects of the food chain safety supervision into one single authority (Soltész, Szőke, \& Balogh 2013). According to Government Decree No.22/2012., the NFCSO is authority for food chain safety, plant production, soil conservation, animal breeding, forestry, hunting, fishery, wine control, agricultural administration, pálinka (Hungarian fruit distillate) control (National Food Chain Safety Office, 2016).

RDEAI was the background institution of the Ministry of Rural Development. In cooperation with the Ministry in the field of educational activities such as central development and service organization, it performed operational tasks and enforcement activities in the field of agriculture.

The Institute's activities are the follows:

- communication with educational institutions, regional, county and local advisory centres;

\footnotetext{
${ }^{1}$ Peter Lengyel

University of Debrecen

lengyel.peter@econ.unideb.hu

${ }^{2}$ István Füzesi

University of Debrecen

fuzesi.istvan@econ.unideb.hu

${ }^{3}$ Ádám Péntek

University of Debrecen

pentek.adam@econ.unideb.hu

${ }^{4}$ Miklós Herdon

University of Debrecen

herdon.miklos@econ.unideb.hu
} 
- assistance of advisory system quality assurance: registering of consultants exam obligations, organization of training courses, developing training materials, documents, software (tests, databases), collecting test results, the developing special advisers qualification proposals;

- Perform administrative tasks with agricultural advisory register.

Our research aims to examine the spread of e-learning applications for further training of agricultural experts, particularly in the human development of agro-technical administrative staff and experts. There have never been any surveys about the application of the e-learning system and the IT skills among the professional consultants. This fact enforced our aim to carry out a research among them. This goal was formulated in 2011, when we conducted a questionnaire survey among the consultants. We repeated the survey in 2015 and the results will be published in this article.

\section{Overview of Learning Management Systems}

Teaching in an E-learning environment can contribute to the ability to teach, the ability to learn and most important to bridge between two main components in the classroom, the teacher and the learner. E-learning provides different environments for learners with dynamic, interactive, nonlinear access to a wide range of information (text, graphics, and animation) as well as to self-directed learning in online communication e-mail and forums (Kotzer \& Elran 2012).

Learning Management Systems (LMS) are information systems running on a server, offering various tools like document publishing, assessment modules, wiki, etc. and LMS can be accessed using a web browser. Within the LMS, educational material is processed, stored and disseminated; teaching and learning related administration and communication is supported (McGill \& Klobas 2009). A LMS is a high solution package that allows for the delivery and administration of content and resources to all students and employees. This system contains software application and features which make learning content easily accessible and managed (Ráthonyi, Várallyai, Nagyné Polyák \& Pető 2014). In addition, it helps instructors to provide their students with learning materials and manages student registration. A LMS provides the platform for this type of learning environment by enabling the management, delivery, tracking of learning, testing, communication, the registration process, and scheduling (Cavus 2013).

Concerning open-source solutions, there are some studies that identify the Moodle (Modular ObjectOriented Dynamic Learning Environment) as the most used platform in higher education, as well as the most easy to use (Paulsen 2003).

\subsection{LMS Statistics}

It is estimated that between the years 2017 and 2018, the LMS market will grow by about $23.17 \%$, with an estimate of growth from $\$ 2.65$ billion in 2013 to $\$ 7.8$ billion in 2018, which is roughly an annual growth rate of $25.2 \%$. Currently, it's a $\$ 2.5$ billion industry in the corporate sector, without calculating revenue from the academic sector, as well. Figure 1 shows that governmental institutions only consists $2 \%$ of the LMS software market, with the educational sector to be approximately one fifth of the entire LMS market (21\%). Other industries follow, such as: technology $12 \%$, manufacturing $9 \%$, consulting and healthcare (7\%) and software development companies (4\%). Finally, non-profit organizations and real-estate are also found at 3\% of the LMS market each. 


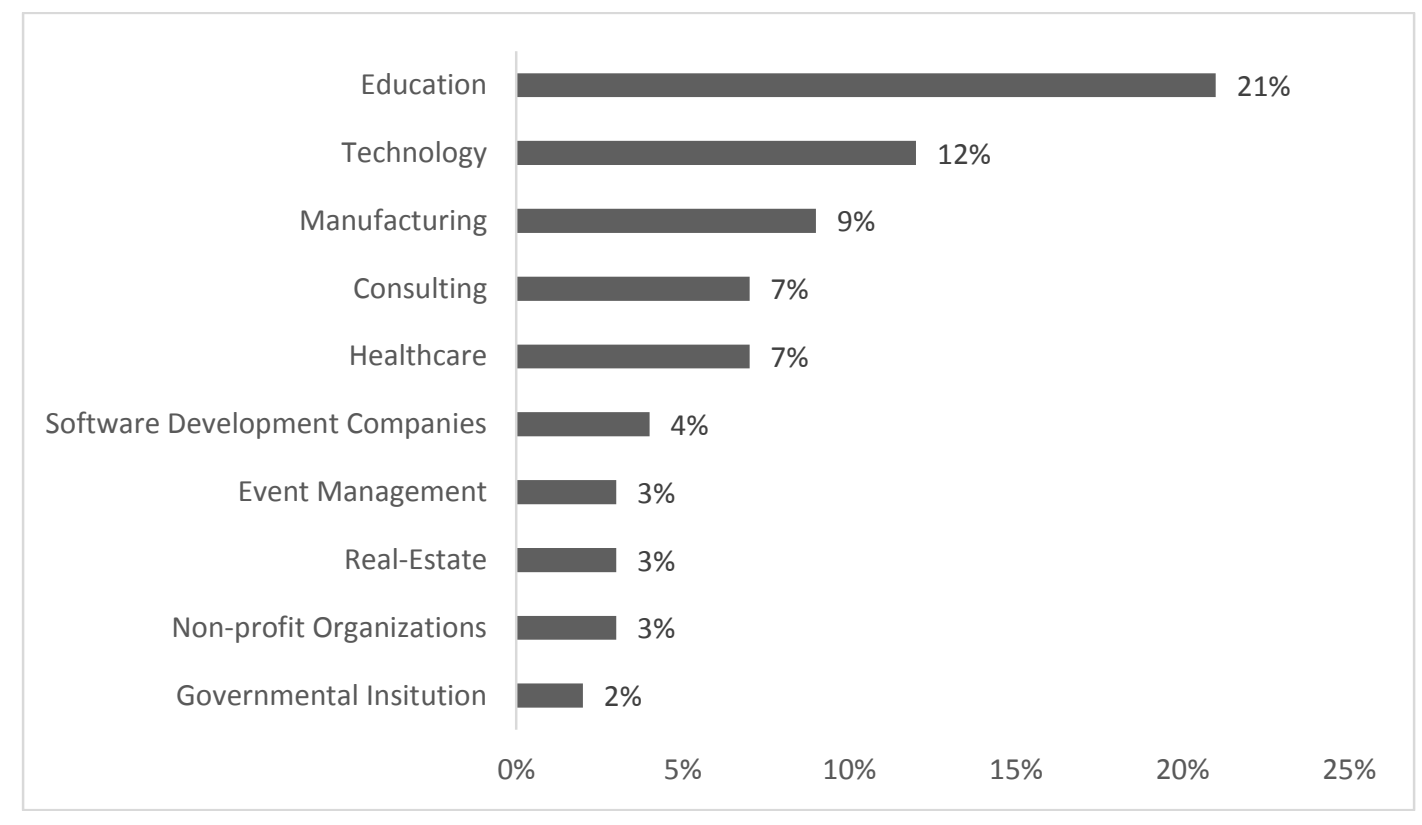

Figure 1. LMS usage per industry (LMS Industry User Research Report 2016)

In terms of actual users, Moodle seems has the most users in the Learning Management System market. It currently boasts an estimated 79.6 million users. Edmodo comes in second and Blackboard rounds out the top 3, with around 20 million users each (Figure 2)

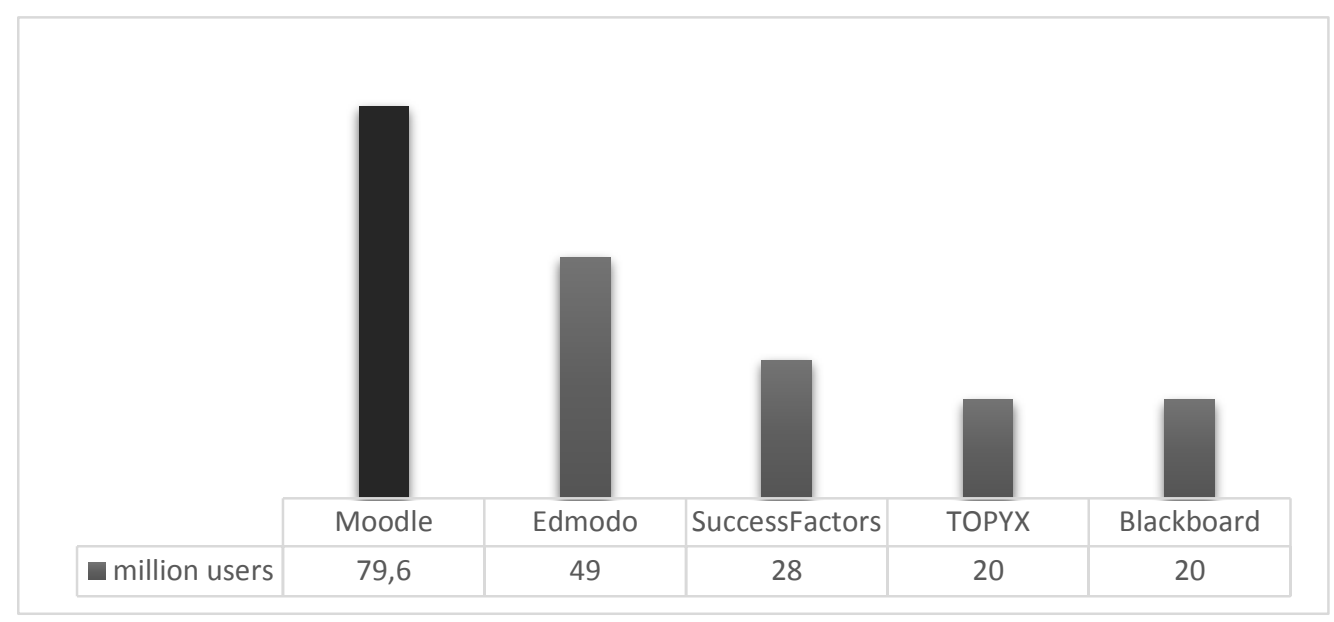

Figure 2. Top 5 LMS by total users (Top LMS Software 2016)

While the number of users is an important factor to keep in mind when selecting a LMS, the number of satisfied customers can give you a clear indication of who is successfully building customer loyalty through effective business practices and a winning product. Edmodo has the largest number of customers, an estimated 120k of them, in fact. Moodle is second on the list, with $87.1 \mathrm{k}$ customers and Collaborize Classroom is third, with 48k customers (Pappas 2015).

\subsection{Moodle platform}

The Moodle represents one of the most widely used open-source e-learning platforms that enables the creation of a course website, ensuring their access only to enrolled students. This platform allows the exchange of information among users geographically dispersed, through mechanisms of synchronous (chats) and asynchronous communication (discussion forums). In a functional perspective, it has easily configurable features, allowing the creation of student assessment processes (quizzes, online tests and surveys), as well as managing their tasks with their timetable (Itmazi, Megías, Paderewski, \& 
Gutiérrez 2005), besides offering a wide variety of complementary tools to support the teaching and learning process.

According the classification presented by the Moodle platform is characterized by a set of functionalities grouped in two different classes: resources and modules. Resources represent instructional materials that are usually created in digital formats and then uploaded to the platform. Web pages, PowerPoint files, word documents, flash animations, video and audio files represent some examples of these resources. Modules are components created via Moodle in order to provide interaction among students and teachers towards manipulation and content transformation (Blin \& Munkro 2008). In this context, the Moodle platform provides several modules, such as Database, Lessons, Assignments, Workshops, Chats, Forums, News, Glossary, Wikis, Choice, Quiz, Survey, Feedback, SCORM (Sharable Content Object Reference Model) and external tools.

\section{Introduction of e-learning system for experts' training}

In addition to traditional forms of training, and built on it there was necessary to establish a distance learning system (e-learning platform), which was extensive multimedia-based solution for the CAO's staff, working in different parts of the country and caring different areas.

E-learning has been introduced under a project. The e-learning (distance learning) pilot training of CAO's professionals started at the end of 2009. The training system was used for the following teaching curriculum (courses):

- Analysis of foodborne illness;

- Rules of Administrative Procedure and General Service;

- Basics of Monitoring;

- Salmonella discharge.

The aim of the training was to test the usability of e-learning system and adaptability to the training system, which was considered as pilot training, but regardless of this study materials and exams themselves are no longer a pilot, but as a live functioned. There were at least two weeks available understanding the curriculums of all courses. In addition to the concrete curriculum on course surface there were placed other related materials, supplementary document templates, rules, guides, video materials in order to expand the knowledge (Vörös \& Lukácsné Veres 2010). Professionals had one week per course to take an exam in each courses. The exam tests included 20 questions, and there were available 45 minutes to finish it. They had achieved more than $50 \%$ for successful exam.

Using e-learning in education of CAO's experts was successful the basis of pilot training. They have gained new knowledge and refreshed their skills. The participants of pilot training had a positive attitude towards trainings implemented in the Distance Learning Framework and still try to take advantage of its benefits. They have been used the system from 2010 .

\section{Applied methods}

The preparation of the questionnaire was preceded by a depth interview. The aim of it was to understand the rules and the system of RDEAI' consultancy testing. During the interview we asked the next questions from the head of the Training and Coordination Department:

1. Since when was electronic learning materials used in the training of consultant?

2. Since when did they use the computer examination?

3. How many consultants took part on the electronic examination? How many times a year?

4. When did you introduce the e-learning?

5. What kind of system do you use, what are the main features?

6. What teaching materials can be found in the system (curricula parties)?

7. How does the testing process?

8. What are the advantages and disadvantages of e-learning examining the consultant point of view?

9. What is the use of e-learning for RDEAI?

10. Did anyone make a survey among the consultants?

Based on the interviews we got the following information: 
The use of computers began in 1995 at the mandatory annual experts training. In this year 'Számadó' examiner computer program was introduced. The program has generated random tests from three types of test question (true/false, multiple choice, matching.). It could be used for practice and examination. During the introduction, the assessment was not rigorous, but after the great reception the evaluation has become more rigorous in next few years. The program was used for testing consultants until 2009.

The growth of Internet use among agricultural experts and the reduction of the available money for the trainings made necessary to establish an efficient, lower-cost training mode (Szilágyi 2012). As a result, the e-learning system of RDEAI (Figure 3) began operating in 2010.

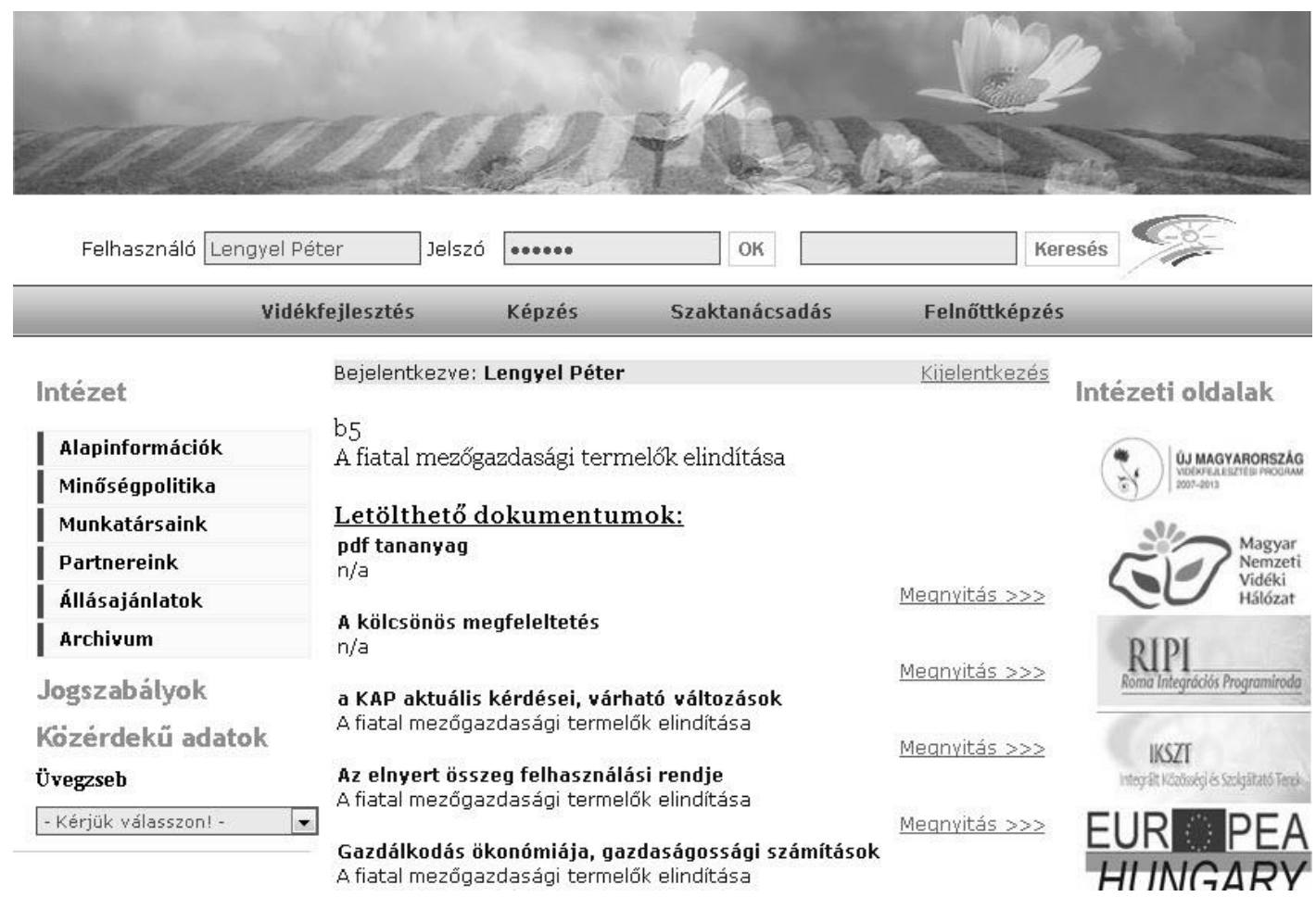

Figure 3. The user interface of RDEAI e-learning system (The Menu: Vidékfejlesztés - Rural development, Képzés - Training, Szaktanácsadás - Extension service, Felnőttképzés - Adult training)

The experts can reach the full training curriculum in the e-learning system. The preparation of consultants for the exams is done individually, but the Regional Advisory Centres provide consultancy to them (RDEAI 2011). The exams of RDEAI - such as the National Advisory Centre - organized and transacted under the scheme. Everybody can use the system with their account. There are possibilities to fill practice test and take exams in the system. At present, the re-registration and registration of agricultural and rural development consultants is underway, which have been managed by Hungarian Chamber of Agriculture (HCA) from October 1, 2014.

Based on the collected information we compiled a questionnaire to get information about the role of Internet in their knowledge, their information technology (IT) skills, the usage of IT communication (ITC) tools, the usage of information database, and their opinion from the advantages of e-learning system. Our questionnaire was accessible through Limesurvey system (Questionnaire to assess the use of e-Learning among consultants 2015), which is a free and open source on-line survey application written in PHP based on a MySQL database. As a web server-based software it enables users using a web interface to develop and publish on-line surveys, collect responses, create statistics, and export the resulting data to other applications (Limesurvey 2016).

\section{Results}

According to the register of consultants the questionnaire was sent to 670 email address. 79 questionnaires were filled out, which is $11.8 \%$ of the total amount. We had 82 answers in 2011, which 
serve as a benchmark for this analysis. Basic IT skills and computer usage are the minimal criteria for the consultants to be able to participate in the electronic exams. So we try to examine their IT skills too.

The respondents could rate themselves about their computer skills by a scale of five, from 1 to 5 . Figure 4 shows that $24 \%$ rated themselves into the category of three, $29 \%$ to four, $43 \%$ to five and only $4 \%$ rated themselves to two in 2015. In total there is an improvement in IT skills compared to 2011.

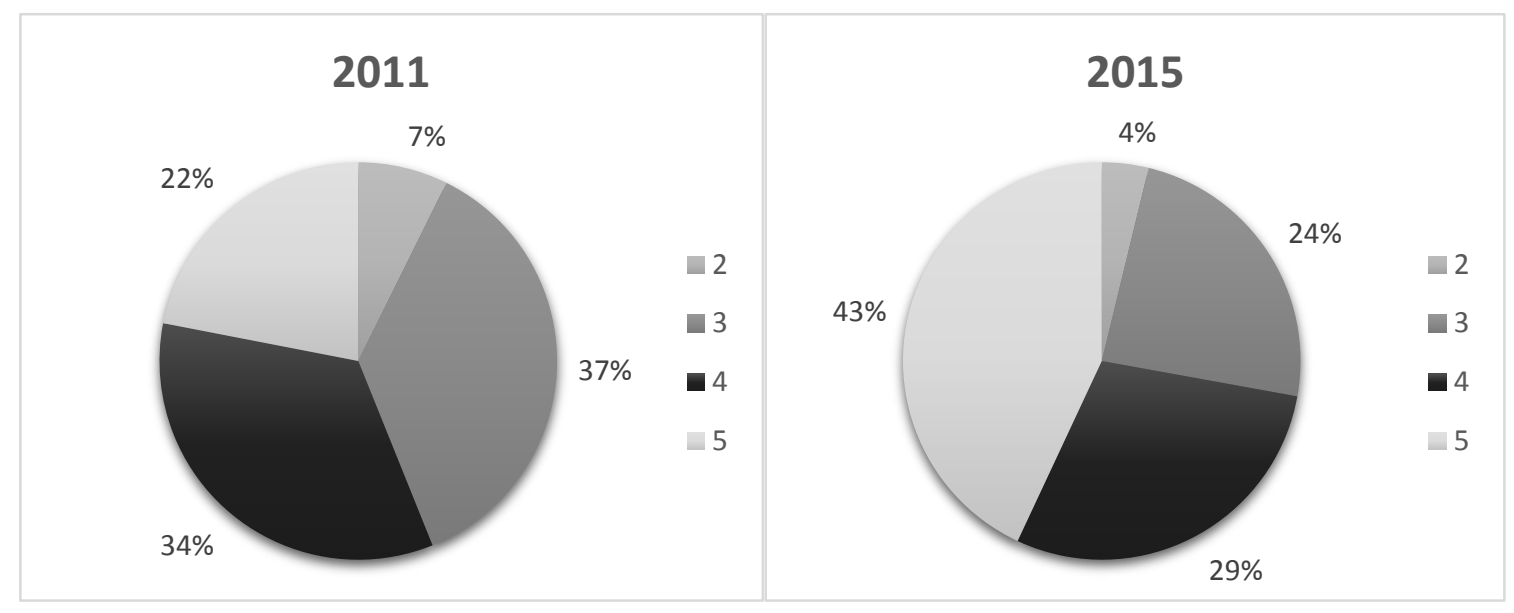

Figure 4. Distribution of IT skills in 2011 and 2015 (1 - Poor, .. , 5 - Excellent)

This means that the consultants have enough IT knowledge to do exams via electronic distance learning and they can serve their information needs using available sources of information on the Internet. This statement is also supported by Figure 5, which indicates that $67 \%$ of the consultants rated the role of the Internet regarding the acquisition of new knowledge by 5 in 2015 . We can see that there is a significant increase at role of Internet.

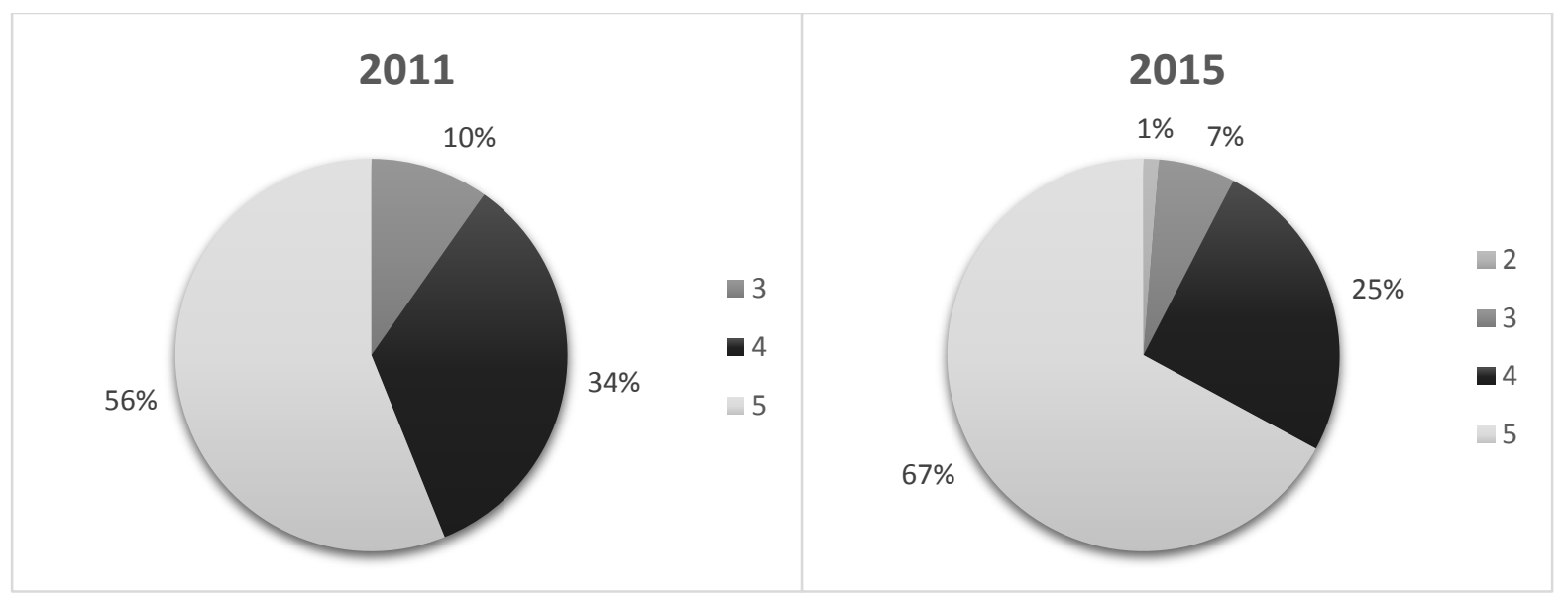

Figure 5. The role of the Internet to get knowledge in 2011 and 2015 (1 - Unimportant, .., 5 - Very important)

Figure 6 represents the sources of information. $78 \%$ of respondents use database from the ARDA and $63 \%$ use database from the NFCSO during their daily work. Agricultural experts have wide variety of information sources and they greatly exploit the online databases. We can see differences in data of 2011 and 2015. There is significant increase for example using Land Office database, National Tax and Customs Administration (NTCA) database and Research Institute of Agricultural Economics (RIAE) information. 


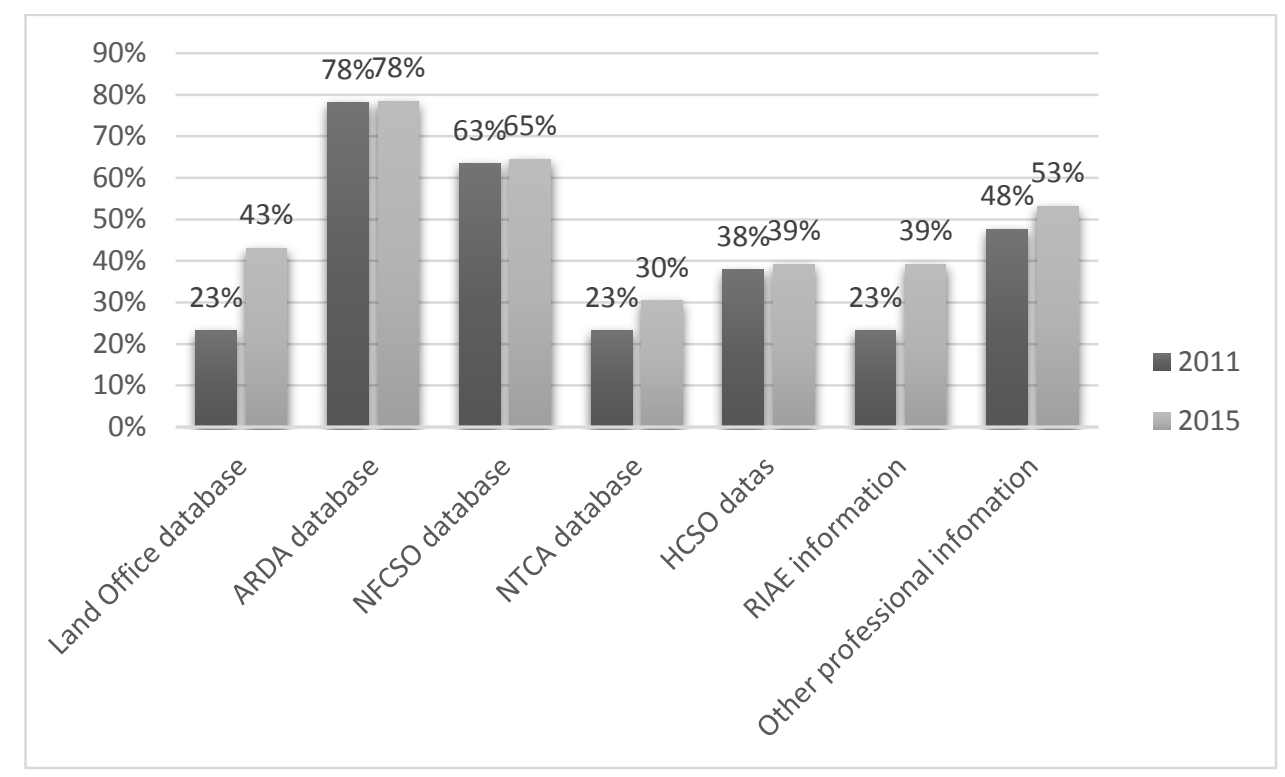

Figure 6. Usage of information source by agricultural experts (ARDA: Agricultural and Rural Development Agency, NFCSO: National Food Chain Safety Office, NTCA: National Tax and Customs Administration, HSCO: Hungarian Central Statistical Office, RIAE: Research Institute of Agricultural Economics)

We can also say that emails have the same role in everyday communication as phones (Figure 7). The benefits of skype are not yet used completely, but we can see a little increase. Statistics also indicate that mainly the experts who are under age of 35 use these type of information technologies. The community places, for example Facebook, Twitter, LinkedIn, are used by the younger generation too, and there is a large increase from 2011 to 2015.

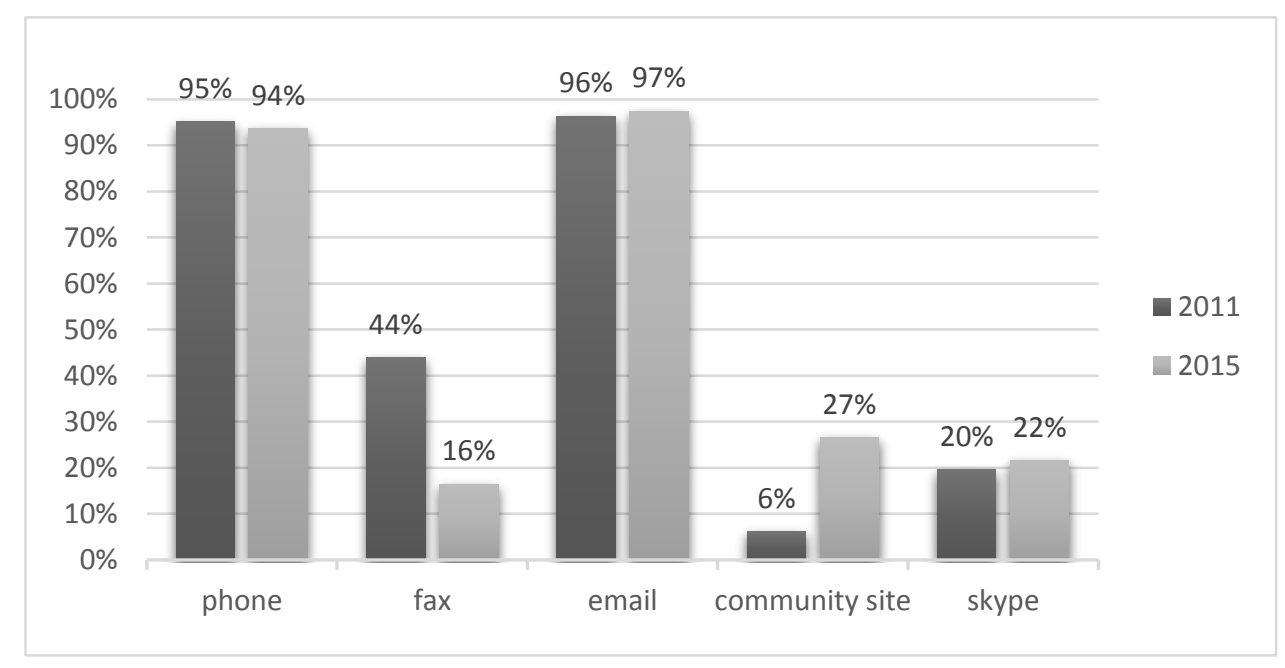

Figure 7. Usage of information technologies by agricultural experts

According to $49 \%$ of the consultants (Figure 8), the most important advantage of the system is the time independent. It is interesting to see that only $10 \%$ of them think that the most important advantage is the cost saving. The most difficult part is the time management and not that they have to have time for examinations. We can say that more and more important the time compared to the cost. 


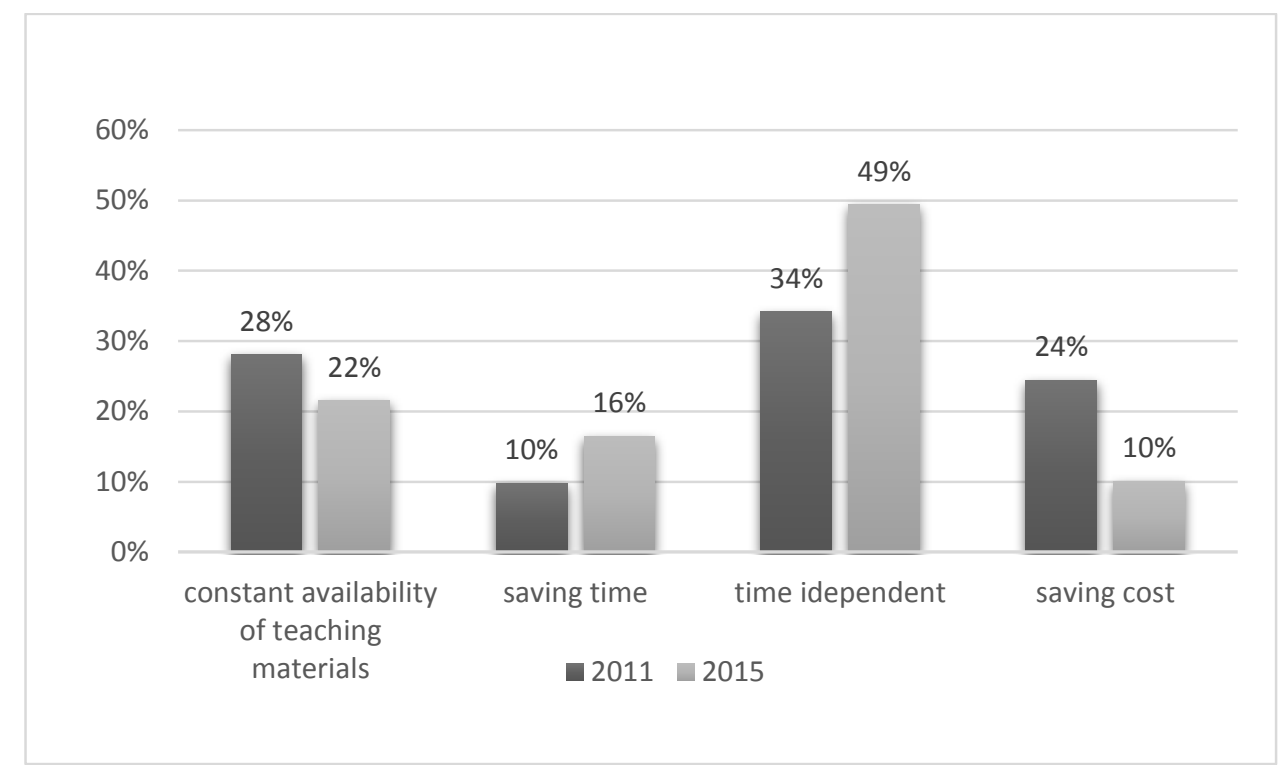

Figure 8. The main advantages of learning system

\section{Conclusion}

The research clearly demonstrates that the introduction of the e-learning system was welcomed positively by the consultants and they recognized its benefits and advantages. We can say that e-learning gradually has a more important role in the training of the agricultural experts and the development of human resources. The survey of IT skills found that there is clear increase in the last 4 years. It may result in other income, which represents an increase in the use of data sources and the use of information technologies. Consequently, there are prerequisites to the e-learning applications can be more and more successful and effective in the future.

\section{References}

Blin, F \& Munro, M 2008, 'Why hasn't technology disrupted academics' teaching practices? Understanding resistance to change through the lens of activity theory.' Computers \& Education, 50(2), pp. 475-490. doi: 10.1016/j.compedu.2007.09.017

Cavus, N 2013, 'Selecting a learning management system (LMS) in developing countries: instructors' evaluation.’ Interactive Learning Environments, 21(5), pp. 419-437. doi: 10.1080/10494820.2011.584321

Itmazi, JA, Megías, MG, Paderewski, P \& Gutiérrez F 2005, 'A comparison and evaluation of open source learning management systems’, IADIS International Conference on Applied Computing, pp. 80-86.

Kotzer, S \& Elran, Y 2012, 'Learning and teaching with Moodle-based e-learning environments, combining learning skills and content in the fields of Math and Science \& Technology.', Proceeding of 1st Moodle Research Conference, pp. 122-131.

Limesurvey From Wikipedia, the free encyclopedia, https://en.wikipedia.org/wiki/LimeSurvey [2016.04.05]

LMS Industry User Research Report, http://www.capterra.com/learning-management-system-software/userresearch [2016.04.07]

McGill, T J \& Klobas, J E 2009, 'A task-technology fit view of learning management system impact.'

Computers \& Education, 52(2), pp. 496-508. doi: 10.1016/j.compedu.2008.10.002

National Food Chain Safety Office, https://www.nebih.gov.hu/en/ [2016.02.01.]

Pappas, C 2015, 'The Top LMS Statistics and Facts For 2015 You Need To Know', http://elearningindustry.com/top-lms-statistics-and-facts-for-2015 [2016.04.05]

Paulsen, M 2003, 'Experiences with Learning Management Systems in 113 European Institutions.' Educational Technology \& Society, 6(4), pp. 134-148. 
Questionnaire to assess the use of e-Learning among consultants http://nodes.agr.unideb.hu/limesurvey/index.php?sid=13987\&lang=hu [2015.12.11]

Ráthonyi, G, Várallyai, L, Nagyné Polyák, I \& Pető, K 2014, Educational experiences of a tourism software (front office system) at the University of Debrecen Journal of Ecoagritourism 10:(1) pp. 160-168.

Rural Development, Education and Advisory Institute http://www.vkszi.hu/ [2011.01.02]

Soltész, A, Szőke, Sz \& Balogh, P 2013, ‘Analysis of economic risks in sow production', Journal of Agricultural Informatics 4:(2) pp. 10-21. doi: 10.17700/jai.2013.4.2.114

Szilágyi, R 2012, 'New information and communication technologies in agriculture - factors, drivers and application possibilities', Journal of Agricultural Informatics 3:(1) pp. 10-18. doi: 10.17700/jai.2012.3.1.77

Top LMS Software, http://www.capterra.com/learning-management-system-software/\#infogra [2016.04.07]

Vörös, Zs \& Lukácsné Veres, E 2010, 'The experience of e-Learning introduction in the CAO - results of a pilot', Journal of Agricultural Informatics 2010 Vol. 1, No. 3, ISSN 2061-862X, pp. 17-28. doi: $\underline{10.17700 / \text { jai.2010.1.3.25 }}$ 